Revista Destaques Acadêmicos, Lajeado, v. 12, n. 2, 2020. ISSN 2176-3070

DOI: http://dx.doi.org/10.22410/issn.2176-3070.v12i2a2020.1883

http://www.univates.br/revistas

\title{
QUEM SÃO OS/AS CONDUTORES/AS COM CNH NO RIO GRANDE DO SUL? QUESTÕES PARA A PSICOLOGIA DO TRÂNSITO
}

\author{
Bárbara Bernardy ${ }^{1}$, Priscila Pavan Detoni ${ }^{2}$
}

\begin{abstract}
Resumo: O comportamento humano é o foco da Psicologia do Trânsito e torna-se fundamental conhecê-lo para a elaboração de medidas de prevenção e promoção na mobilidade urbana. Neste sentido, este estudo tem como objetivo conhecer quem são os condutores com carteira nacional de habilitação $(\mathrm{CNH})$ através de dados sociodemográficos, para que a Psicologia do Trânsito possa atuar no Estado do Rio Grande do Sul. Foi utilizado o método quantitativo, com análise do banco de dados do departamento estadual de trânsito do Rio Grande do Sul (DETRAN/RS), mantido pela companhia de processamento de dados do Estado do Rio Grande do Sul (PROCERGS), referente aos dados sobre idade e gênero dos condutores e números de infrações e acidentes do ano de 2017. Os resultados mostram que a maioria dos condutores são do gênero masculino, com idade entre 31 a 35 anos e idosos com mais de 65 anos, os condutores que mais cometem infrações são do gênero masculino com idade entre 26 a 40 anos e o maior índice de acidentes com vítimas fatais envolve homens com idade entre 21 a 29 anos. Evidenciou-se carência de pesquisas na área, e necessidade de maior prevenção na área da Psicologia do Trânsito focada na população jovem e masculina.
\end{abstract}

Palavras-chave: Psicologia do Trânsito. Condutores/as. Gênero. Idade. Prevenção.

1 Psicóloga pela Universidade Federal de Santa Maria (UFSM); Especialista em Gestão em Organização Pública de Saúde pela UFSM: Psicóloga no Centro de Atenção Psicossocial álcool e outras drogas III (CAPSAD III) em Santa Cruz do Sul - RS: Psicóloga perita examinadora do trânsito pela Universidade de Santa Cruz do Sul (UNISC), credenciada no Departamento Estadual de Trânsito do Rio Grande do Sul (DETRAN-RS): cursando especialização em Psicologia do Trânsito pela Universidade do Vale do Taquari (UNIVATES). E-mail: barbarabernardy@hotmail.com.

2 Professora orientadora. Psicóloga, Mestre e Doutora em Psicologia Social e Institucional pela Universidade Federal do Rio Grande do Sul (UFRGS); Membro do Núcleo de Pesquisa em Relações de Gênero e Sexualidade (Nupsex/UFRGS) e do Centro de Referência em Direitos Humanos: Relações de Gênero, Diversidade Sexual e de Raça (CRDH/UFRGS); Docente na Universidade do Vale do Taquari de Ensino Superior (Univates). Conselheira Titular do Conselho Regional de Psicologia do Rio Grande do Sul (CRP 07 - Gestão 2016-2019), coordena Comissão de Direitos Humanos. 


\section{INTRODUÇÃO}

Desde o início do reconhecimento e regulamentação da Psicologia no Brasil, que data de 1962, uma das primeiras áreas de atuação do Psicólogo foi a Psicologia do Trânsito (SILVA, 2012), que pode ser definida como o estudo científico do comportamento dos participantes do trânsito e tem como finalidade, contribuir com melhorias para o mesmo, onde a partir de um melhor conhecimento do homem poder auxiliar nas situações das estradas, aperfeiçoamento dos veículos, diminuição dos acidentes de trânsito e também dando as diretrizes educacionais (ROZESTRATEN, 1981). Mas mesmo a Psicologia do Trânsito sendo uma área ampla, no Brasil ainda está muito centrada na avaliação de condutores por meio de testes psicológicos, o que a torna alvo de críticas devido à escassez de instrumentos psicológicos validados e normatizados para a área do trânsito no país e também pela falta de definição sobre o perfil do motorista brasileiro (RUEDA, 2017).

Para que a Psicologia do Trânsito possa contribuir com a mobilidade urbana, atuando nas políticas públicas de trânsito, nas discussões municipais, estaduais e federais, faz-se necessário conhecer quem são os condutores. $\mathrm{O}$ fator humano sempre estará presente na mobilidade urbana, reconhecê-lo como um processo coletivo é imprescindível e o psicólogo através de seu conhecimento técnico, poderá auxiliar nas relações que se estabelecem neste coletivo assim como nas intervenções deste processo interdisciplinar e intersetorial, não podendo "pensar o trânsito com o conhecimento de um único saber profissional, mas com as diversas áreas do conhecimento" (MARIUZA; GARCIA, 2010, p. 13). Essa pesquisa tem como objetivo conhecer quem são os condutores com carteira nacional de habilitação $(\mathrm{CNH})$ através de dados sociodemográficos, para que a Psicologia do Trânsito possa atuar no Estado do Rio Grande do Sul. Os dados analisados serão sobre idade e gênero dos condutores, além dos números de infrações e acidentes do ano de 2017.

Para compreender o ser humano, além de estudar seu corpo e sua origem animal, é necessário pesquisar principalmente, como ele se constitui em um contexto sociocultural (STREY, et al., 2013). Para pensar numa intervenção social nas relações do cotidiano, Freitas (2008), entende como uma ação implicada da relação partícipe e partilhada, entre agentes (internos e externos), quanto à problematização da realidade e à elaboração de alternativas a serem implementadas através de processos de formação e capacitações de lideranças. De acordo com Thielen, Hartmann e Soares (2008, p. 131), o trânsito, "tornase uma forma de controle demográfico ardilosa, constituindo-se na segunda maior causa de mortalidade no país".

Ao considerar o trânsito um sistema de normas convencionadas que objetiva a segurança dos usuários. O Código de Trânsito Brasileiro no seu $\& 1^{\circ}$ Considera trânsito a utilização das vias por pessoas, veículos e animais, isolados ou em grupos, conduzidos ou não, para fins de circulação, parada, 
estacionamento e operação de carga ou descarga. Ainda no Art. 26. Os usuários das vias terrestres devem:

I - abster-se de todo ato que possa constituir perigo ou obstáculo para o trânsito de veículos, de pessoas ou de animais, ou ainda causar danos a propriedades públicas ou privadas; II - abster-se de obstruir o trânsito ou torná-lo perigoso, atirando, depositando ou abandonando na via objetos ou substâncias, ou nela criando qualquer outro obstáculo.

Art. 27. Antes de colocar o veículo em circulação nas vias públicas, o condutor deverá verificar a existência e as boas condições de funcionamento dos equipamentos de uso obrigatório, bem como assegurar-se da existência de combustível suficiente para chegar ao local de destino.

Art. 28. O condutor deverá, a todo momento, ter domínio de seu veículo, dirigindo-o com atenção e cuidados indispensáveis à segurança do trânsito.

No entanto, não é somente a lei que rege as ações dos motoristas, as questões sociais que ocorrem a sua volta estabelecem regras informais de conduta em função das necessidades e motivações dos indivíduos que vivem em determinada comunidade. Rocha Martin e Galvão (2011, p. 392) observam que "o estímulo que provoca e mantém as ações do motorista situa-se no mundo em volta dele" e acrescenta que o motorista manifesta formas de expressão do grupo ao qual pertence. Estas formas culturais não interfeririam somente no espaço físico onde os fenômenos sociais ocorrem, mas em toda a dinâmica social onde o motorista toma parte, "especialmente aquelas regras e hábitos informais (tais como impunidade e uma 'especial' maneira brasileira de viver) que organiza as relações entre os diferentes atores da circulação" (ROCHA; MARTIN; GALVÃO, 2011, p. 392).

Corroborando com o grande desafio que é o desenvolvimento das práticas em comunidade para produzir determinados impactos psicossociais na vida cotidiana das pessoas, e ainda mais, para que sigam dando continuidade ao seu processo de envolvimento e participação comunitária, com um forte compromisso coletivo (FREITAS, 2008). Neste sentido, a contribuição da Psicologia do Trânsito para a qualidade da mobilidade urbana no Brasil, está principalmente no que se refere ao trabalho psicológico preventivo no contexto do trânsito. Compreendendo o trânsito como fenômeno humano que procura manter a sociedade ativa e produtiva, no qual ocorre o ápice de uma interação humana profundamente paradoxal, gerando encontros e desencontros de uma espécie que pretende assim permanecer em constante mobilidade, constituindo as relações e estabelecendo os parâmetros para as trocas no seu meio social (MARIUZA; GARCIA, 2010).

Refletir a respeito do papel que a Psicologia vem cumprindo na área do trânsito e repensar o seu lugar de uma forma mais abrangente nessa 
multiplicidade e complexidade de fenômenos que envolvem o trânsito torna-se fundamental. E é com o intuito de favorecer essa reflexão, que essa pesquisa visa pensar em possibilitar novas estratégias de intervenção para a Psicologia do Trânsito no Estado do Rio Grande do Sul.

\section{MÉTODO}

Para esse estudo utilizou-se a abordagem quantitativa que tem como objeto de estudo os fatos (vistos e descritos) e o estabelecimento matemático das relações causa-efeito, buscando explicação do comportamento das coisas. O comportamento é o estudo classificatório de tipos de atitudes, assim como manifestações físicas, psíquicas ou sociais, ambos observáveis em indivíduos ou grupos como respostas a estímulos intrapessoais ou ambientais (TURATO, 2005).

Foi discutido conforme os dados estatísticos do banco de dados do Departamento Estadual de Trânsito - DETRAN/RS, mantido pela Companhia de Processamento de Dados do Estado do Rio Grande do Sul - PROCERGS, disponível no seu Porta (http://www.detran.rs.gov.br). Foram utilizados os documentos referentes aos Condutores do RS; Infrações no RS; Perfil dos condutores do RS, Infrações por características do condutor e acidente com vítimas fatais, contendo o quantitativo total de condutores do Estado do Rio Grande do Sul, bem como, o número de vítimas fatais e o total de condutores que cometem infrações e suas diferenças por gênero e faixa etária.

Primeiramente, foi analisado quantitativamente os condutores quanto ao gênero e classificado em feminino e masculino somente, seguido pela análise de faixa etária, tempo de habilitação, se exerce atividade remunerada e tipo de habilitação por categoria. Após foram analisados os dados referentes às infrações de trânsito quanto a multa mais cometida, diferença por gênero, faixa etária e se exerce atividade remunerada, em seguida analisou-se o número de vítimas fatais referente a idade e gênero. Foram utilizadas para análise as tabelas do último ano e de interesse do estudo, com os dados referentes ao ano de 2017.

\section{RESULTADOS}

O número total de condutores no Estado do Rio Grande do Sul no ano de 2017 foi de 4.884.183, com uma população total estimada em 11.322 .895 segundo dados do Instituto Brasileiro de Geografia e Estatística - IBGE. Sendo que, 1.660.373 deste total é do gênero feminino, corresponde a 33,99\% e 3.223.810 é do gênero masculino, corresponde a $66 \%$. A idade de maior prevalência entre as condutoras do gênero feminino é dos 31 a 35 anos, totalizando 241.056. Entre os condutores do gênero masculino prevalece a idade acima de 65 anos, totalizando 463.657. Somando os dois gêneros a idade da maioria dos 
condutores é de 31 a 35 anos, somando o número de 604.148, e, acima de 65 anos, somando 602.585. Conforme Figura 1 e Figura 2.

Figura 1 - Condutores por faixa etária no RS - posição atual

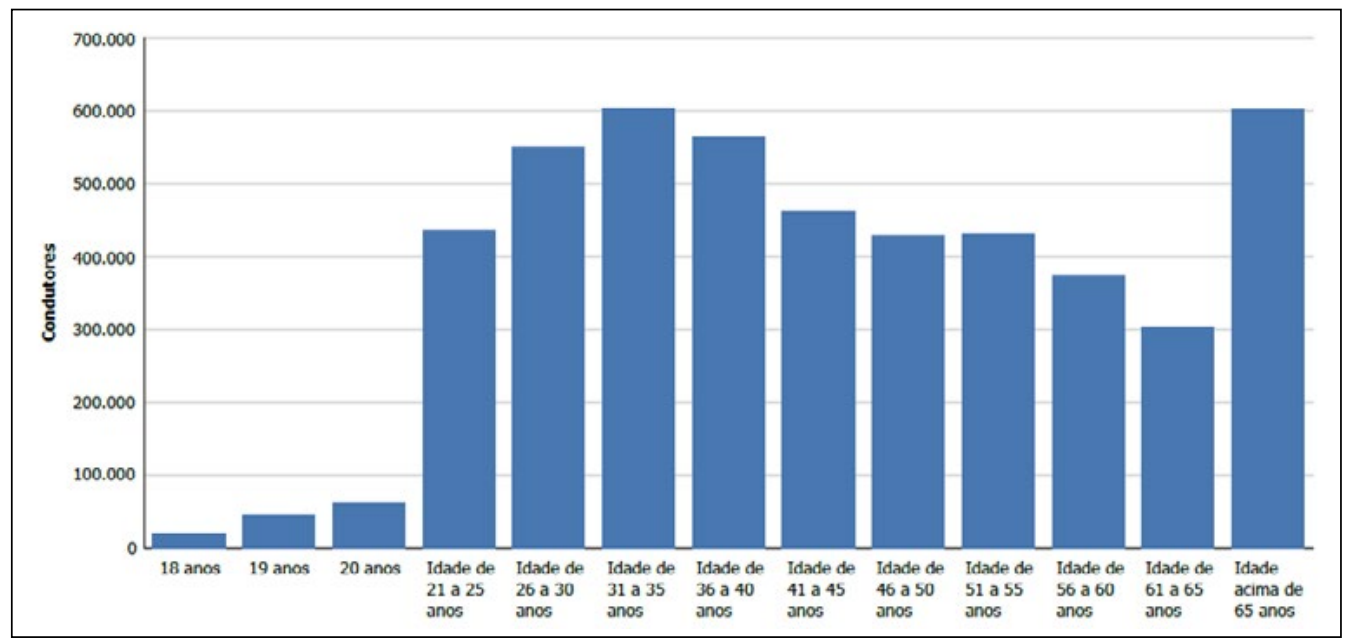

Assessoria Técnica, Gestão e Planejamento

Fonte de dados: PROCERGS

Relatório gerado em: 23/01/2018

Figura 2 - Condutores por Gênero no RS ao ano

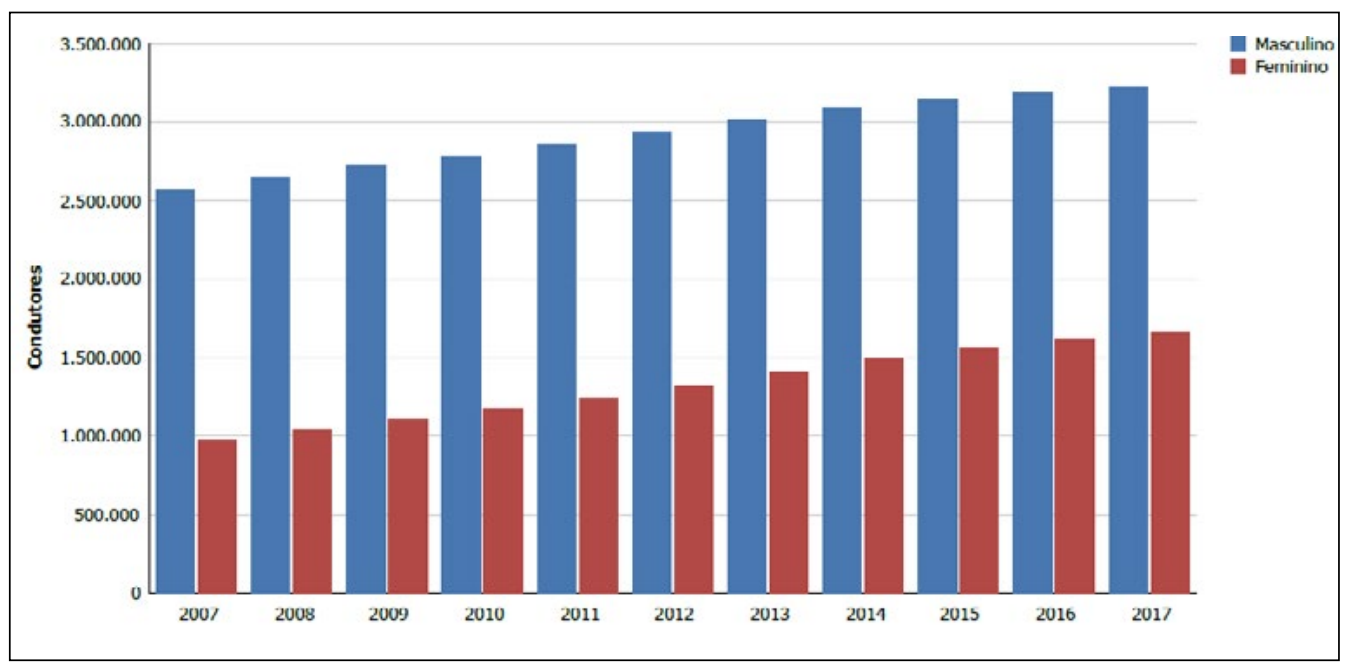

Assessoria Técnica, Gestão e Planejamento

Fonte de dados: PROCERGS

Relatório gerado em: 23/01/2018 
Considerando o tempo de habilitação, mais de 1.600 dos condutores do Estado são habilitados a mais de 20 anos e $85 \%$ não exercem atividade remunerada. Sendo que 55\% (2.692.944) dos condutores do RS tem habilitação para a categoria B. De acordo com a Figura 3 e a Figura 4.

Figura 3 - Condutores por tempo de habilitação - posição atual

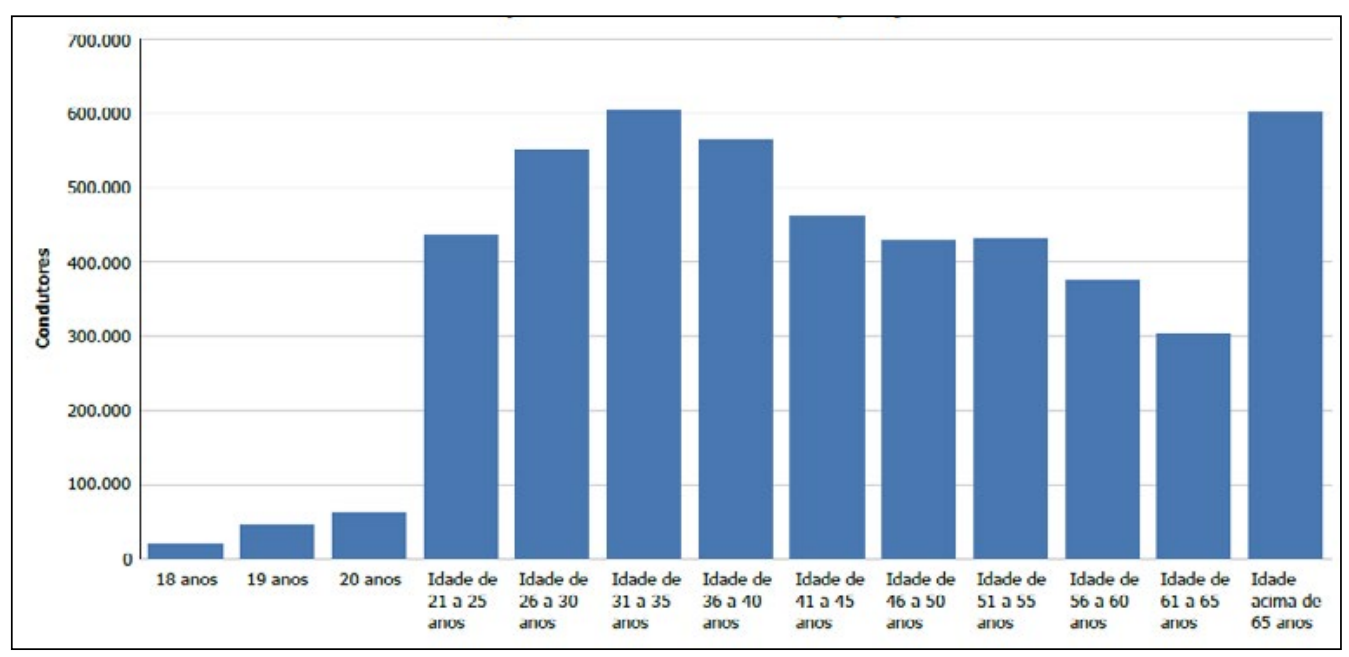

Assessoria Técnica, Gestão e Planejamento

Fonte de dados: PROCERGS

Relatório gerado em: 23/01/2018

Figura 4 - Distribuição \% atividade remunerada na $\mathrm{CNH}$ - posição atual

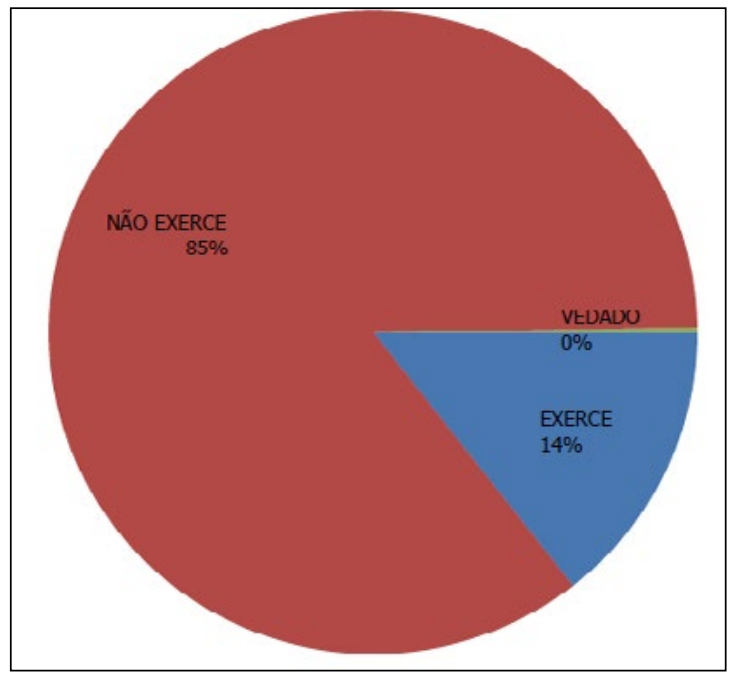

Assessoria Técnica, Gestão e Planejamento

Fonte de dados: PROCERGS

Relatório gerado em: 23/01/2018 
No estado do Rio Grande do Sul no ano de 2017 foram contabilizadas um total de 3.159.381 infrações de trânsito, sendo que 1.489.142 corresponde ao artigo 181 do Código de Trânsito Brasileiro - CTB que é "Transitar em velocidade superior à máxima permitida para o local, medida por instrumento ou equipamento hábil, em rodovias, vias de trânsito rápido, vias arteriais e demais vias". Dos condutores que cometem infrações de trânsito $72,60 \%$ são do gênero masculino e $27 \%$ do gênero feminino, a faixa etária com maior prevalência é a idade de 31 a 35 anos perfazendo 13,79\% dos infratores, seguida da idade de 36 a 40 anos com $12,86 \%$ e da idade de 26 a 30 anos com $12,26 \%$. A grande maioria dos condutores infratores, ou seja $81 \%$, não exercem atividade remunerada como motorista. Conforme seguem as Figuras 5, 6, 7 .

Figura 5 - Condutores infratores por faixa etária - 2017 até dezembro

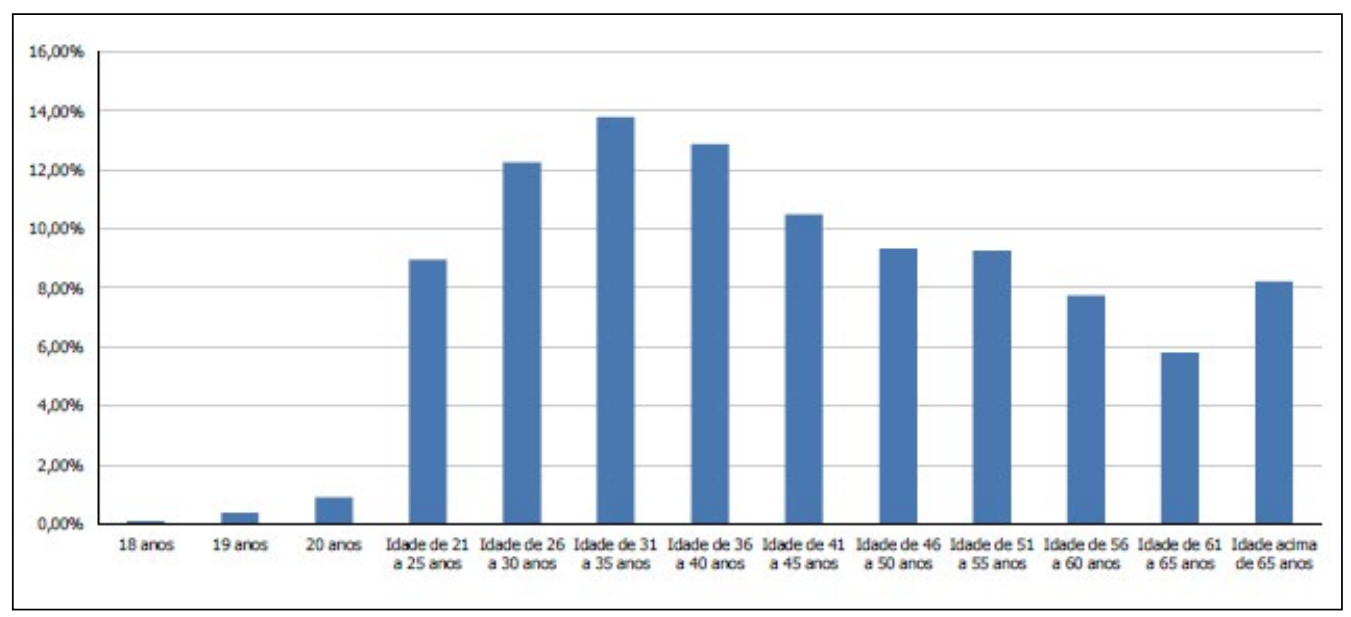

Assessoria Técnica, Gestão e Planejamento

Fonte de dados: PROCERGS

Relatório gerado em: 23/01/2018 
Figura 6 - Condutores infratores por gênero

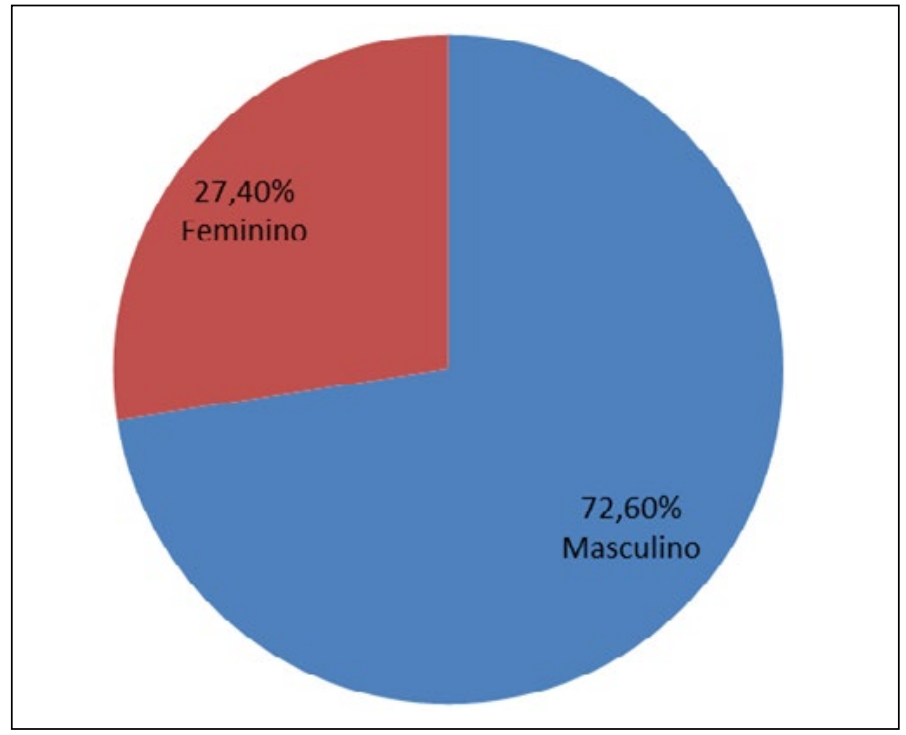

Assessoria Técnica, Gestão e Planejamento

Fonte de dados: PROCERGS

Relatório gerado em: 23/01/2018

Figura 7 - Distribuição de infrações por atividade remunerada na CNH - 2017 até dezembro

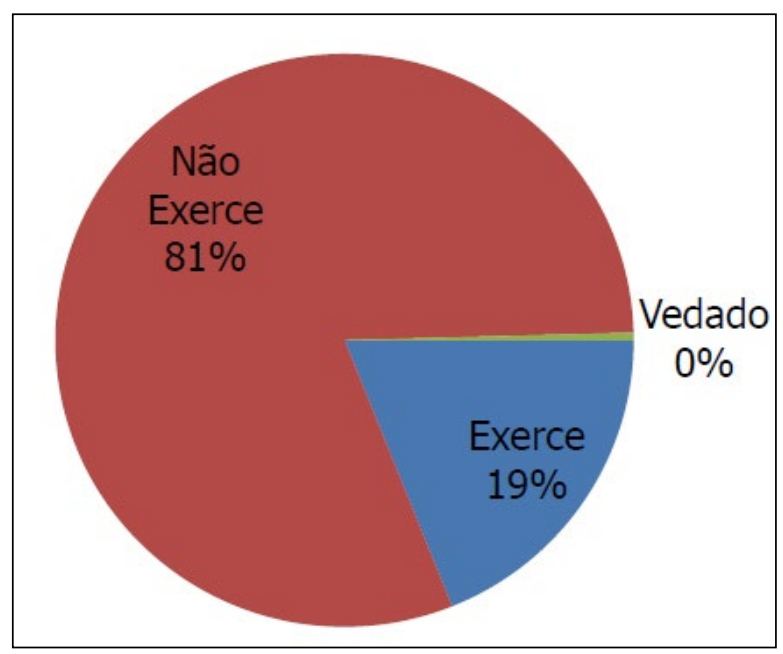

Assessoria Técnica, Gestão e Planejamento

Fonte de dados: PROCERGS

Relatório gerado em: 23/01/2018 
Referente aos dados sobre acidentalidade com vítimas fatais, a Figura 8 mostra que no ano de 2017 morreram no Estado do Rio Grande do Sul 1.741 pessoas, sendo que 22,4\% (390) do gênero feminino e $77,6 \%$ (1351) do gênero masculino. A faixa etária com o maior número de vítimas se concentra entre 21 e 24 anos 10,3\% (180), seguida da idade entre 25 e 29 anos 10,1\% (176), conforme mostra a Figua 9.

Figura 8 - Vítimas fatais por gênero

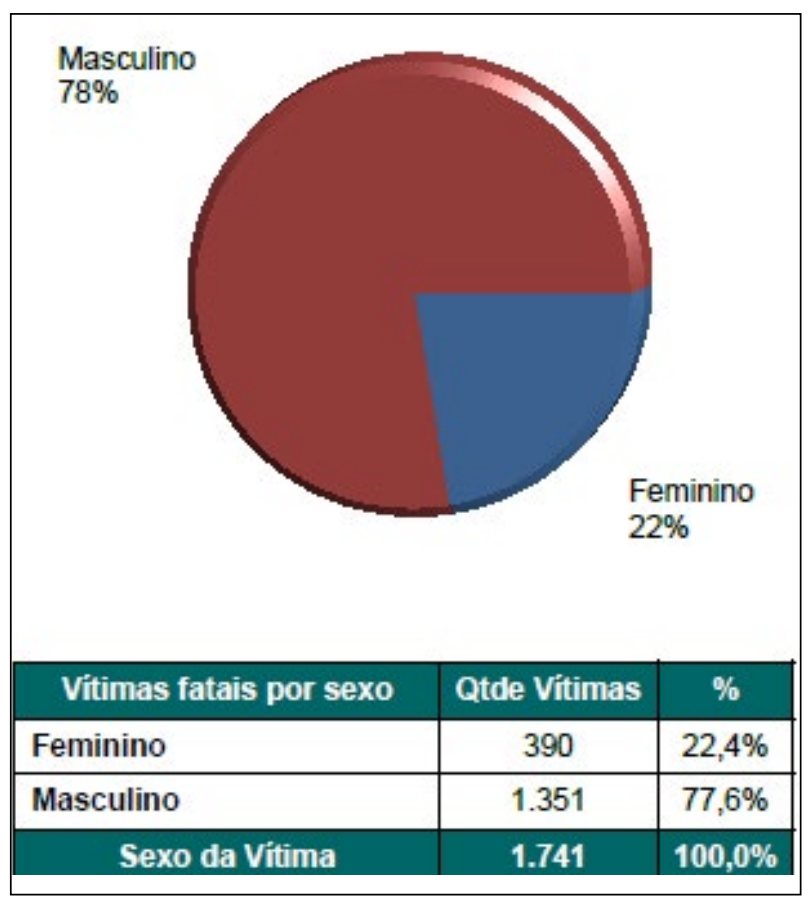

Assessoria Técnica, Gestão e Planejamento

Fonte de dados: PROCERGS

Relatório gerado em: 23/01/2018 
Figura 9 - Vítimas fatais por faixa etária

\begin{tabular}{|c|c|c|}
\hline $\begin{array}{c}\text { Vítimas fatais por faixa } \\
\text { etária }\end{array}$ & Qtde Vítimas & $\%$ \\
\hline $\mathbf{0 - 1 0}$ & 36 & $2,1 \%$ \\
\hline $\mathbf{1 1 - 1 4}$ & 24 & $1,4 \%$ \\
\hline $15-17$ & 46 & $2,6 \%$ \\
\hline $18-20$ & 118 & $6,8 \%$ \\
\hline $21-24$ & 180 & $10,3 \%$ \\
\hline $25-29$ & 176 & $10,1 \%$ \\
\hline $30-34$ & 155 & $8,9 \%$ \\
\hline $35-39$ & 171 & $9,8 \%$ \\
\hline $40-44$ & 109 & $6,3 \%$ \\
\hline $45-49$ & 124 & $7,1 \%$ \\
\hline $50-54$ & 122 & $7,0 \%$ \\
\hline $55-59$ & 119 & $6,8 \%$ \\
\hline $60-64$ & 99 & $5,7 \%$ \\
\hline $65-74$ & 146 & $8,4 \%$ \\
\hline $75+$ & 110 & $6,3 \%$ \\
\hline Não informado & 6 & $0,3 \%$ \\
\hline Total & 1.741 & $\mathbf{1 0 0 , 0 \%}$ \\
\hline & & \\
\hline
\end{tabular}

Assessoria Técnica, Gestão e Planejamento Fonte de dados: PROCERGS

Relatório gerado em: 23/01/2018

\section{DISCUSSÃO DOS RESULTADOS}

Um dos principais problemas econômicos e sociais atualmente é o comportamento no trânsito, há um crescimento progressivo do número de veículos nas ruas, o que não acontece na mesma proporção com a oferta de vias, provocando congestionamentos, conflitos para a ocupação de espaços e acidentes. Fator, este, que impacta na qualidade de vida do sujeito, principalmente nos grandes centros (CUELLAR, 2014).

Ainda no Brasil, há um agravante como a falta de civilidade por parte dos pedestres e motoristas, produzindo uma cultura arraigada de desrespeito às leis de trânsito. "Hoje, apesar de haver uma legislação bem mais desenvolvida, 
o que se observa é a insegurança e total desrespeito dos motoristas pela sua própria vida e a dos outros" (CUELLAR, 2014, p. 104).

Roberto da Matta afirma isso quando diz:

A imprudência, o descaso e a mais chocante e irreconhecível incivilidade brasileira no trânsito decorre da ausência de uma visão igualitária do mundo, justamente num espaço inevitavelmente marcado e desenhado pela igualdade mais absoluta entre seus usuários, como ocorre com as ruas e avenidas, as estradas e viadutos (MATTA, 2010, P. 20).

No entanto, os meios de controle e as infrações de trânsito são temas polêmicos, e como encontrar meios de torná-lo menos violento, está relacionado a cumprir as normas que visam a segurança de motoristas e pedestres, o que acaba se tornando o grande desafio da sociedade atual.

De acordo com os resultados encontrados nesta pesquisa, o Estado do Rio Grande do Sul tem 4.884.183 condutores com carteira nacional de habilitação, mantendo uma diferença significativa de número de habilitados entre homens 3.223.810 e mulheres 1.660.373, bem como nos resultados relacionados às infrações de trânsito, masculino: $72,60 \%$ e feminino: $27,40 \%$ e também no que diz respeito a acidentes fatais 1.358 homens, representando $77,6 \%$ e 390 mulheres, representando $22,4 \%$.

Nas situações de trânsito, onde o aparecimento dos fatores de riscos ficam potencializados, o gênero é um fator de diferenciação importante na condução, as mulheres ainda refletem no trânsito comportamentos herdados da sua história social e familiar, sendo mais sociáveis. Enquanto os homens são mais competitivos, constituem um grupo de risco devido a características da personalidade que os levam a subestimar o perigo e a conduzir de modo agressivo (CORREIA; HORTA, 2014).

Ainda segundo os autores, os homens cometem mais infrações e mais acidentes do que as mulheres, mas existe uma maior pressão social no sexo masculino do que no feminino no que diz respeito à condução de risco, principalmente ao excesso de velocidade. As mulheres mesmo podendo irritar-se mais por serem mais cuidadosas, quando observam comportamentos impróprios de outros motoristas adotam um conjunto de respostas mais adaptativas e seguras do que os homens (CORREIA; HORTA, 2014).

De acordo com estudos realizados por no que se refere a variável gênero, verificou-se que:

Os homens acreditam mais na sua capacidade para dirigir e se valem de mecanismos para transformar o seu ato prejudicial no trânsito em uma boa conduta, distorcendo os seus efeitos maléficos por meio de justificativas socialmente aceitas com objetivo de evitar penalidades 
em benefício próprio. Apresentam, também, incapacidade de avaliar as situações que envolvem risco e tendem a buscar por sensações novas, consequentemente tendem a ter maior envolvimento em acidentes de trânsito. (MOGNON; SANTOS, 2014, p. 463).

Pesquisa realizada por Luiza Neto (2009), sobre justificativas de motoristas para infrações de trânsito, foi constatado que há um predomínio dos homens contestando as multas recebidas nas solicitações de recursos aos órgãos competentes, o que pode ser indicativo, para Mognon e Santos (2014), da justificação da sua conduta ao volante, com possível autojulgamento positivo sobre a habilidade no trânsito e a não aceitação da ocorrência.

Estas diferenças encontradas nos dados sociodemográficos sustentam certa formação identitária reafirmando valores sociais constituídos de estereótipos entre os gêneros, onde determinados padrões emocionais e comportamentais definem o que seria um homem e o que seria uma mulher, sendo que traços de caráter relacional, onde geralmente, renúncia sexual e beleza estética são mais valorizados nas mulheres, enquanto que virilidade e capacidade laborativa são mais valorizados nos homens. As mulheres são destinadas a uma existência mais silenciosa, o que está relacionado a maior segurança e os homens destinados a uma existência construída no imperativo, precisando provar a todo momento que se é homem, assumindo uma postura ativa e consequentemente de maior impulsividade (COSTA; ZANELLO, 2015). Essa divisão sexual é modulada histórica e socialmente e diz respeito ao que nos foi ensinado ao longo dos anos, os homens designados à esfera produtiva, com funções de maior valor social e as mulheres à esfera privada e reprodutiva (HIRATA; KERGOAT, 2007).

Referente aos dados encontrados quanto à faixa etária, há uma prevalência no Estado do Rio Grande do Sul de condutores com CNH com idade entre 31 e 35 anos 604.148 e idosos acima de 65 anos 602.585, sendo que, a maior incidência de acidentalidade com vítimas fatais concentra-se na idade de 21 a 29 anos, representado 20,4\%, e o maior índice de infrações de trânsito, $38,91 \%$ ocorrem entre os 26 anos até os 40 anos de idade, demonstrando que apesar de ser em números quase a mesma proporção, apenas 8\% dos idosos cometem ato infracional.

No Brasil é estabelecido que a partir dos 65 anos de idade há uma diminuição na periodicidade do tempo de renovação da habilitação, embora a idade não é fator decisivo na avaliação da aptidão dos idosos condutores de veículos. A resolução do CONTRAN n ${ }^{\circ} 007 / 98$ estipula que a avaliação médica para a renovação da carteira de habilitação deve ser realizada periodicamente de cinco em cinco anos para todos os motoristas e a partir dos 65 anos de idade passa a ser exigido a cada três anos.

$\mathrm{O}$ ato de dirigir trata-se de uma atividade complexa, que requer habilidades cognitivas, comportamentais, sensório-perceptivas e físicas. E está 
diretamente relacionado a independência e ao controle da própria vida, por meio da condução de veículos automotores muitos idosos conseguem cumprir os seus papeis sociais (LENARDT et al,, 2018).

Conforme os mesmos autores, pesquisas realizadas na área mostraram que ao comparar jovens e idosos, estes últimos tiveram pontuação inferior nos testes cognitivos, porém nos testes de direção o desempenho foi igual. Em relação aos padrões de condução dos idosos foi identificado que com o passar dos anos, tendem a dirigir menos, evitam dirigir a noite, optam por distâncias mais curtas e raramente em horário de grande movimento. De acordo com Mognon e Santos (2014), quando os motoristas idosos percebem a diminuição das capacidades cognitivas, sentem-se menos confiantes e evitam dirigir.

O motorista se sente mais confiante na direção quanto maior a frequência semanal que dirige, o que pode contribuir consequentemente, com maior envolvimento em acidentes e multas. $\mathrm{O}$ excesso de confiança nas habilidades de dirigir nos jovens tende a contribuir com comportamentos de risco, enquanto para os motoristas idosos, há a falta de confiança em dirigir com segurança. Ainda foi identificado que os jovens até planejam suas ações futuras, mas buscam novas sensações e não avaliam as situações que podem envolver risco, enquanto os idosos refletem sobre suas ações, o que pode justificar os dados encontrados (MOGNON; SANTOS, 2014).

Os comportamentos inadequados dos mais jovens no trânsito podem estar relacionados ao que preconiza o ideal moderno numa luta contra o tempo, com exigência de eficiência e de resultados, tendendo a agir nele de forma impulsiva, acelerada e ansiosa, encarando o ambiente do trânsito sem qualquer valor em si, apenas como mais uma etapa a ser rapidamente vencida. Os jovens do sexo masculino possuem alta quilometragem anual e estimam-se como melhores motoristas (LIMA; CAVALCANTE, 2015). Ainda características comportamentais como imaturidade, audácia, tendência de superestimar capacidades, inexperiência na condução e sensação de invulnerabilidade estão ligadas à idade e a gravidade de acidentes de trânsito (SILVEIRA; SOUZA, 2016).

\section{CONCLUSÃO}

A partir de dados sociodemográficos, foi possível conhecer um pouco mais sobre os 4.884 .183 condutores com carteira nacional de habilitação no estado do Rio Grande do Sul. Há uma prevalência do gênero masculino ao feminino no número de carteiras de motoristas, o que pode ser resquício de uma herança social histórica. A faixa etária predominante é entre 31 a 35 anos e idosos com mais de 65 anos. São motoristas experientes, a maioria com mais de 20 anos de habilitação na categoria $B$, a qual permite dirigir veículos como automóvel, caminhonete, camioneta e utilitário e que não exercem atividade remunerada como motoristas. 
Os condutores que mais cometem infrações são do gênero masculino com idade entre 26 a 40 anos e o maior índice de acidentes com vítimas fatais envolve homens com idade entre 21 a 29 anos. Desta forma, os motoristas homens jovens representam a maior parte de acidentes com vítimas fatais. E mais da metade destes motoristas gaúchos cometem infrações de trânsito, o que pode estar conectado a uma existência social construída no imperativo, resultando num comportamento de maior impulsividade, aliado ao predomínio das características dos mais jovens de imaturidade, audácia e percepção de risco prejudicada, sinônimo de virilidade (COSTA; ZANELLO, 2015). Além disso, a maioria dos infratores não são motoristas profissionais, ou seja, não exercem atividade remunerada dirigindo.

Também se evidencia que o número de idosos com mais de 65 anos é quase o mesmo que os condutores entre 31 a 35 anos, e no entanto, a prevalência de infrações entre os mais jovens é bem maior que entre os idosos o que pode ser justificado pelo uso de comportamentos compensatórios pelos idosos, tais como, dirigir com menos frequência, evitar dirigir a noite, optar por distâncias mais curtas e raramente em horário de grande movimento.

Portanto, é notório que a população de risco do estado do Rio Grande do Sul se concentra no público masculino e jovem. Por isso, considera-se que as medidas preventivas para minimizar os riscos devem, indispensavelmente, voltar as campanhas para este público. O Projeto Vida no Trânsito (PVT) já é uma iniciativa brasileira voltada para a vigilância e prevenção de lesões e mortes no trânsito e promoção da saúde, em resposta aos desafios da Organização das Nações Unidas (ONU) para a Década de Ações pela Segurança no Trânsito 2011 - 2020 e é coordenado pelo Ministério da Saúde, em uma articulação interministerial e parceria com a Organização Pan Americana da Saúde (Opas), foi lançado em 2010 e tem como foco das ações a intervenção em dois fatores de risco priorizados no Brasil: dirigir após o consumo de bebida alcoólica e velocidade excessiva e/ou inadequada, além de outros fatores ou grupos (MINISTÉRIO DA SAÚDE, 2017).

Espera-se que com os resultados encontrados neste estudo, a Psicologia do Trânsito possa contribuir para pensar além das testagens, mas considerar o quanto os sujeitos são construídos pelas questões de gênero e pertencimento a uma determinada faixa etária estão atrelados aos comportamentos no trânsito, para elaborar estratégias e ações junto às políticas públicas de trânsito e mobilidade urbana.

Considerando que o trânsito é um espaço coletivo de circulação e convivência entre pessoas, veículos e animais, é necessário ponderar que este estudo utilizou apenas os dados sociodemográficos dos condutores com $\mathrm{CNH}$ no ano de 2017, o que dá uma visão parcial e temporal dos envolvidos no trânsito, evidenciando a carência de pesquisas na área e indicando a necessidade de estudos mais amplas com outras populações como pedestres, ciclistas e 
demais que circulam no trânsito, bem como, a identificação da variabilidade populacional e territorial do Estado.

\section{REFERÊNCIAS}

CORREIA, José Poças; HORTA, Maria da Purificação Cunha. Personalidade e comportamentos de risco de motoristas: diferenças entre sexos. Psicologia: teoria e prática, v. 16, n. 1, p. 79-90, 2014. Disponível em: <http:/ / pepsic.bvsalud.org/scielo. php?script=sci_arttext\&pid $=$ S1516-36872014000100007\&lng=pt\&tlng=pt $>$. Acesso em: 10 abr. 2018.

CUELLAR, kip. Direitos humanos e cidadania no transito brasileiro. Revista de Administração de Roraima - RARR, v. 4, n. 1, p. 103-118, 2014. Disponível em: <http://dx.doi.org/10.18227/rarr.v4i1.2127>. Acesso em: 14 abr. 2018.

BRASIL. Lei n. 9.503, de 23 de setembro de 1997. Institui o Código de Trânsito Brasileiro. Disponível em: <http://www.planalto.gov.br/ccivil_03/Leis/19503.htm>. Acesso em: 12 abr.2018.

FREITAS, Maria Fátima Quintal. Ética e paradigmas na psicologia social: Práxis e ética na psicologia social comunitária: possibilidades de transformação social na vida cotidiana. In: PLONER, KS. et al. (Org.). Ética e paradigmas na psicologia social. Rio de Janeiro: Centro Edelstein de Pesquisas Sociais, 2008.

HIRATA, Helena; KERGOAT, Danièle. Novas configurações da divisão sexual do trabalho. Cadernos de Pesquisa, v. 37, n. 132, p. 595-609, 2007. Disponível em: $<$ https://dx.doi.org/10.1590/S0100-15742007000300005

http:/ / portalms.saude.gov.br/saude-de-a-z/acidentes-e-violencias/41896-projetovida-no-transito $>$. Acesso em: 11 abr. 2018.

LENARDT, Maria H. et al. Idosos não frágeis e a habilitação para dirigir veículos automotores. Revista Brasileira de Enfermagem, v. 71, n, 2, p. 350-356, 2018. Disponível em:<https://dx.doi.org/10.1590/0034-7167-2016-0675>. Acesso em: 12 abr. 2018.

LIMA, Ana Inez Oka Elvas; CAVALCANTE, Sylvia. Tempo e Trânsito na Experiência Subjetiva de Motoristas. Psicologia: Ciência e Profissão, n. 35, v. 1, p. 125-138, 2015. Disponível em: <https://dx.doi.org/10.1590/1982-3703000412013>. Acesso em: 12 abr. 2018.

LUIZA NETO, Ingrid. Justificativa de motoristas para infrações de trânsito: esboçando um modelo. 2009. 107 f. Dissertação (Mestrado em Psicologia) Universidade de Brasília, Brasília, 2009.

MARIUZA, Clair Ana; GARCIA, Lucio Fernando (Org.). Trânsito e mobilidade humana: Psicologia, Educação e Cidadania. Porto Alegre: Ideograf/Conselho Regional de Psicologia do Rio Grande do Sul, 2010. 
MATTA, Roberto; VASCONCELOS, João Gualberto; PANDOLFI, Ricardo. Fé em Deus e pé na tábua (Ou como e por que o trânsito enlouqueceu no Brasil). Rio de janeiro: Editora Rocco, 2010.

MOGNON, Jocemara Ferreira; SANTOS, Acácia Aparecida Angeli. Autoeficácia para dirigir, desengajamento moral e impulsividade em motoristas. Psico-USF, v. 19, n. 3, p. 457-466, 2014. Disponível em:<https:/ / dx.doi.org/10.1590/141382712014019003008>. Acesso em: 10 abr. 2018.

ROCHA, João Bosco de Assis; MARTIN, William Lee Berdel; GALVÃO, Olavo de Faria. Relação entre valores e o comportamento de motoristas no trânsito. Temas em Psicologia, v. 19, n. 2, p. 391-403, 2011. Disponível em: <http:/ / pepsic.bvsalud.org/ scielo.php?script=sci_arttext\&pid=S1413-389X2011000200004\&lng=pt\&tlng=pt $>$. Acesso em: 10 abr. 2018.

ROZESTRATEN, Reinier J. A. Psicologia do trânsito: o que é e para que serve. Psicologia: ciência e profissão, v. 1, n. 1, p. 141-143, 1981. Disponível em: <http:/ / pepsic.bvsalud.org/scielo.php?script=sci_arttext\&pid=S1414-98931981000100006\&lng $=$ pt\&tlng=pt $>$. Acesso em: 10 abr.2018.

RUEDA, Fabián Javier Marín. Evidências de validade de critério para testes de atenção na avaliação psicológica no contexto do trânsito. Avaliação Psicológica, v. 16, n. 2, p. 234-240, 2017. Disponível em:<https:/ /dx.doi.org/10.15689/AP.2017.1602.14>. Acesso em: 10 abr. 2018.

SILVA, Fábio Henrique Vieira de Cristo. A Psicologia do trânsito e os 50 anos de profissão no Brasil. Psicologia: Ciência e Profissão, v. 32, spe, p. 176-193, 2012.

Disponível em: <https:/ / dx.doi.org/10.1590/S1414-98932012000500013>. Acesso em: 10 abr. 2018.

SILVEIRA, Jucimara Zararias Martins; SOUZA, José Carlos Rosa Pires. Sequelas de Acidentes de Trânsito e Impactos na Qualidade de Vida. Revista Saúde e Pesquisa, Maringá, v. 9, n. 2, p. 373-380, maio/ago., 2016.

STREY, Marlene N. et al. Psicologia Social Contemporânea. 21. ed. Petrópolis, RJ: Vozes, 2013.

TURATO, Egberto Ribeiro. (2005). Métodos qualitativos e quantitativos na área da saúde: definições, diferenças e seus objetos de pesquisa. Revista de Saúde Pública, v. 39, n. 3, p. 507-514, 2005. Disponível em: <https:/ /dx.doi.org/10.1590/S003489102005000300025>. Acesso em: 12 abr. 2018.

THIELEN, Iara Picchioni; HARTMANN, Ricardo Carlos; SOARES, Diogo Picchioni. Percepção de risco e excesso de velocidade. Cadernos de Saúde Pública, v. 24, n. 1, p. 131-139, 2008. Disponível em:<https:/ /dx.doi.org/10.1590/S0102311X2008000100013>. Acesso em: 10 abr.2018.

ZANELLO, Valeska; FIUZA, Gabriela; COSTA, Humberto Soares. Saúde mental e gênero: facetas gendradas do sofrimento psíquico. Fractal: Revista de Psicologia, v. 27, n. 3, p. 238-246, 2015. Disponível em: <https://dx.doi.org/10.1590/1984-0292/1483>. Acesso em: 12 abr. 2018. 